\title{
Simulating the Effect of Nonframework Cations on the Adsorption of Alkanes in MFI-type Zeolites
}

\author{
Edith Beerdsen, ${ }^{\dagger}$ David Dubbeldam, ${ }^{\dagger}$ Berend Smit, ${ }^{\dagger}$ Thijs J. H. Vlugt,, and Sofía Calero $^{*, \dagger}$ \\ Department of Chemical Engineering, University of Amsterdam, Nieuwe Achtergracht 166, \\ 1018 WV Amsterdam, The Netherlands, and Department of Interfaces, Utrecht University, Padualaan 8, \\ 3584 CH Utrecht, The Netherlands \\ Received: May 6, 2003; In Final Form: July 9, 2003
}

\begin{abstract}
We performed configurational-bias Monte Carlo (CBMC) simulations for the adsorption of methane, ethane, propane, butane, and isobutane in MFI-type zeolites with different concentration and nature of nonframework cations. Additional molecular simulations for a mixture of butane/isobutane in these MFI-type zeolites were carried out. The effect of the content-density and nature-of nonframework cations was systematically analyzed, and our results show that even though all of the MFI-type zeolites are structurally similar, differences in the size and concentration of the nonframework cations lead to differences in their adsorptive properties and selectivity performance. For a given cation, the adsorption of alkanes in MFI increases with decreasing the nonframework cation concentration, and for a given Si/Al ratio, the adsorption of alkanes in MFI increases with decreasing atomic weight of the nonframework cation.
\end{abstract}

\section{Introduction}

Zeolites are microporous materials that have found widespread use in several technological fields. Because of their peculiar structural characteristics (three-dimensional lattice with well-defined pores of molecular dimensions, high internal surface area and curvature, high ion-exchange capacity, and remarkable thermal stability), zeolites act as efficient heterogeneous catalysts, as adsorbents, and as molecular sieves in gas separation processes. ${ }^{1,2}$ An additional feature of these materials is the possibility to tune their structures to each particular application by choosing zeolites with cavities or channels or both of suitable shape and dimension and by introducing appropriate nonframework cations within the pores.

Among the numerous synthetic zeolites or molecular sieves known to date, MFI-type zeolites are widely studied and commercially important. , $^{3,4}$ MFI-type zeolites are used as highly selective catalysts and as agents for the synthesis of chemicals. ${ }^{5}$ Zeolites consist of a network of $\mathrm{TO}_{4}$ tetrahedrals $(\mathrm{T}=\mathrm{Si}$ or $\mathrm{Al}$ ) linked by oxygen atoms. Isomorphic substitution of silicon with aluminum atoms generates negative charges on the framework that have to be neutralized by protons or countercations. The preferential location of these cations is well defined and corresponds to the optimization of the crystal potential energy. ${ }^{6}$ However, these cations are mobile and they may move from one site to another in the presence of adsorbed molecules such as water or organics. ${ }^{7,8}$ The framework topology of MFI can be synthesized with a composition range $8 \leq \mathrm{Si} / \mathrm{Al} \leq \infty$, and it is composed of a three-dimensional network pore system with straight, parallel channels intersected by zigzag channels and with 10-membered rings of oxygen atoms controlling the entrance to the channels. ${ }^{4,9}$ At room temperature, this zeolite typically has an orthorhombic symmetry (space group Pnma) with 12 distinct crystallographic T-sites. ${ }^{10}$

Because of their medium pore size, approximately $5.3 \AA$ A ${ }^{11}$ MFI-type zeolites are useful for separation processes because

\footnotetext{
* To whom correspondence should be addressed. E-mail: calero@ science.uva.nl

University of Amsterdam.

$\doteqdot$ Utrecht University.
}

their openings are approximately the same size as the kinetic diameter of many molecules. Hence, they can separate gas mixtures with high selectivities. Separation is possible by molecular sieving, preferential adsorption, or differences in diffusion rates. High separation selectivities have been reported for isomers of organic molecules. ${ }^{12-15}$

In the past few years, molecular simulations have played an important role in augmenting our understanding of the relation between microscopic and macroscopic properties of confined molecular fluids in zeolites. ${ }^{16}$ In particular, Monte Carlo simulations are capable of accurately predicting adsorption isotherms of linear and branched hydrocarbons ${ }^{17-21}$ and mixtures of alkanes ${ }^{22,23}$ in zeolites. The adsorption capacity of the zeolites is known to vary with both the zeolite type and the nonframework cation distribution. Previous experimental ${ }^{24}$ and molecular simulation $^{25}$ results on adsorption of alkanes in MFI-type zeolites indicate that for all adsorbates decreasing the nonframework cation density (by increasing the framework $\mathrm{Si} / \mathrm{Al}$ ratio) increases the loading at a given pressure. The adsorption selectivity of a mixture of isomers also depends on the zeolite structure and on the density and location of nonframework cations. MFI consists of intersecting channel structures of medium pore size where configurational entropy favors the adsorption of the linear isomer. ${ }^{15}$ Moreover, experiments show that the linear/branched separation selectivity increases with increasing nonframework cation density inside MFI-type channels. ${ }^{13,26-28}$ To the best of our knowledge, only a few groups have performed molecular simulations in MFI-type structures with alkali metal nonframework cations. ${ }^{29-33}$ This may be because the commercial interest for alkali-exchanged MFI zeolites has been less than that for LTA and FAU (structures used to separate oxygen from air in pressure swing adsorption ${ }^{34}$ ). However, alkali metal exchanged MFI zeolites are currently used in the adsorption of alkanes, alkyl alcohols, hydroxyl alcohols, alkylamines, organic acids, acetaldehyde, ethyl ether, acetone, nitriles, CO, ethyl acetate, and aromatics ${ }^{35-38}$. It has also been found that the cracking of aromatics such as silanes can modify the MFI pore structure to obtain a higher 
TABLE 1: Lennard-Jones Parameters Defining the Cations Interactions ${ }^{a}$

\begin{tabular}{|c|c|c|c|c|c|c|c|c|c|c|c|c|}
\hline \multirow[b]{2}{*}{ cation } & \multicolumn{2}{|c|}{ cation-cation } & \multicolumn{2}{|c|}{ cation $-\mathrm{O}_{\text {zeo }}$} & \multicolumn{2}{|c|}{ cation- $\mathrm{CH}$} & \multicolumn{2}{|c|}{ cation- $-\mathrm{CH}_{2}$} & \multicolumn{2}{|c|}{ cation- $-\mathrm{CH}_{3}$} & \multicolumn{2}{|c|}{ cation- $-\mathrm{CH}_{4}$} \\
\hline & $\sigma[\AA]$ & $\epsilon / k_{\mathrm{B}}(\mathrm{K})$ & $\overline{\sigma[\AA]}$ & $\epsilon / k_{\mathrm{B}}(\mathrm{K})$ & $\sigma[\AA]$ & $\epsilon / k_{\mathrm{B}}(\mathrm{K})$ & $\overline{\sigma[\AA]}$ & $\epsilon / k_{\mathrm{B}}(\mathrm{K})$ & $\overline{\sigma[\AA]}$ & $\overline{\epsilon / k_{\mathrm{B}}(\mathrm{K})}$ & $\sigma[\AA]$ & $\epsilon / k_{\mathrm{B}}(\mathrm{K})$ \\
\hline $\mathrm{Li}^{+}$ & 2.18 & 12.6 & 2.57 & 26.2 & 3.19 & 11.2 & 2.93 & 24.1 & 2.86 & 35.1 & 2.85 & 43.2 \\
\hline $\mathrm{Na}^{+}$ & 2.33 & 46.8 & 2.65 & 50.4 & 3.30 & 21.6 & 3.03 & 46.4 & 2.96 & 67.7 & 2.95 & 83.2 \\
\hline $\mathrm{K}^{+}$ & 3.02 & 18 & 3.02 & 31.3 & 3.76 & 13.4 & 3.45 & 28.8 & 3.36 & 42 & 3.36 & 51.6 \\
\hline $\mathrm{Cs}^{+}$ & 3.3 & 22.7 & 3.16 & 35.1 & 3.93 & 15.1 & 3.61 & 32.3 & 3.52 & 47.2 & 3.51 & 58 \\
\hline $\mathrm{Ca}^{2+}$ & 2.98 & 78.5 & 3.00 & 65.3 & 3.73 & 28.0 & 3.43 & 60.1 & 3.34 & 87.7 & 3.33 & 107.8 \\
\hline $\mathrm{Ba}^{2+}$ & 3.82 & 226.3 & 3.4 & 110.9 & 4.23 & 47.6 & 3.88 & 102 & 3.78 & 148.9 & 3.77 & 183 \\
\hline
\end{tabular}

${ }^{a}$ All other parameters considered in this work (alkane-alkane and alkane-zeolite interactions) are taken from our previous work. ${ }^{51}$

adsorption selectivity of $\mathrm{H}_{2} \cdot{ }^{39}$ Our previous studies on alkaliexchanged MFI structures have focused on $\mathrm{Na}^{+}$as the nonframework cation. ${ }^{25}$ In the present paper, the adsorption of $\mathrm{C}_{1}-$ $\mathrm{C}_{4}$ alkanes over various alkali and alkali earth metal exchanged MFI-type zeolites is studied using configurational-bias Monte Carlo (CBMC) simulations. We use here common nonframework cations such as $\mathrm{Li}^{+}, \mathrm{Na}^{+}, \mathrm{K}^{+}, \mathrm{Cs}^{+}, \mathrm{Ca}^{2+}$, and $\mathrm{Ba}^{2+}$ to systematically analyze the influence of both nature and density of these nonframework cations on the adsorptive properties and the selectivity performance of MFI-type zeolites. We focus on $\mathrm{C}_{1}-\mathrm{C}_{4}$ alkanes because the use of small molecules avoids the computational burden associated with longer molecules while still allowing us to compare the adsorptive properties.

The remainder of the paper is arranged as follows. In section 2, we present the details of our simulation methodology, including descriptions of the potential parameters used. In section 3 , we present the results of our simulations. These include adsorption isotherms and Henry coefficients for methane, ethane, propane, butane, and isobutane and adsorption isotherms for a mixture of butane/isobutane in several MFI structures varying the nonframework cation type and concentration. A detailed analysis and a discussion of the results are also presented in this section. Finally, we give some concluding remarks in section 4 .

\section{Simulation Details}

In this work, we analyze the effect of the nature and density of the nonframework cations on the adsorption behavior of alkanes in MFI-type structures using molecular simulations. Five MFI unit cell compositions with $\mathrm{Si} / \mathrm{Al}=11,18.2,23,47$, and $\infty$ corresponding to eight, five, four, two, and zero aluminum atoms per unit cell (Al/uc) of, in total, 96 tetrahedral atoms per unit cell (silicon and aluminum) were modeled. The negative charges introduced by replacing $\mathrm{Si}$ by $\mathrm{Al}$ were compensated by alkali $\left(\mathrm{Li}^{+}, \mathrm{Na}^{+}, \mathrm{K}^{+}\right.$, and $\left.\mathrm{Cs}^{+}\right)$or alkali earth metal cations $\left(\mathrm{Ca}^{2+}\right.$ and $\left.\mathrm{Ba}^{2+}\right)$. We have defined our systems with static atomic charges (and thus neglecting polarizability) that are assigned by choosing $q_{\mathrm{Li}, \mathrm{Na}, \mathrm{K}, \mathrm{Cs}}=+1, q_{\mathrm{Ca}, \mathrm{Ba}}=+2, q_{\mathrm{Si}}=+2.05$, and $q_{\mathrm{Al}}=+1.75$ (resulting in $q_{\mathrm{Si}}-q_{\mathrm{Al}}=0.3$ ). ${ }^{40}$ Different charges are used for oxygen atoms bridging two silicon atoms, $q_{\mathrm{OSi}}$, and oxygens bridging one silicon and one aluminum atom, $q_{\mathrm{OAl}}$. The charge $q_{\mathrm{OSi}}$ is obtained using the relation $q_{\mathrm{Si}}+\left(2 q_{\mathrm{OSi}}\right)$ $=0$, ensuring that the zeolite is neutral in the absence of aluminum, while $q_{\mathrm{OAl}}$ is chosen in such a way that the total charge of the system is equal to zero. ${ }^{25,41}$ Several authors have performed simulations using flexible zeolites ${ }^{16,42-46}$ showing that a flexible lattice can influence diffusion properties. To diffuse inside a zeolite, the molecules have to go through channels and intersections forming energy barriers. In a flexible zeolite, the fluctuations of the framework can change the height of these energy barriers. However, our study focuses at the lowenergy equilibrium configurations, so the fluctuations in the higher-energy configurations in flexible zeolite models are negligible. ${ }^{43}$ Even though our zeolite lattices are rigid during the simulations, interactions of nonframework cations with framework atoms, other sodium cations, and alkane molecules have been considered. This allows the nonframework cations to move freely in the system.

The adsorption isotherms of alkanes were computed using CBMC simulations in the grand-canonical ensemble. ${ }^{47,48} \mathrm{We}$ have performed calculations in which the interactions of the atoms inside the zeolite are modeled by Lennard-Jones and Coulombic interactions. The alkanes are described with a united atom model, in which each $\mathrm{CH}_{n}$ group is treated as a single interaction center. ${ }^{49}$ The interactions between these pseudoatoms are given by Lennard-Jones potentials in which the parameters are chosen to accurately reproduce experimental data (vapor liquid equilibrium of alkanes ${ }^{50}$ and heats of adsorption and Henry coefficients in silicalite ${ }^{51}$ ). The interactions of the adsorbed molecules with the zeolite are dominated by the dispersive forces between the pseudo-atoms and the oxygen atoms of the zeolite, ${ }^{52,53}$ meaning that the silicon interactions are taken into account through an effective potential with only the oxygens. The nonframework cations are also described as single interaction centers, but these are charged, unlike the united atoms of the hydrocarbons. Table 1 lists all of the LennardJones parameters used in this work. ${ }^{51,54}$ The Coulomb interactions in the system are calculated using the Ewald summation. ${ }^{48}$

In the CBMC algorithm, molecules are grown bead by bead, avoiding overlaps. For each bead, a set of trial orientations according to the internal energy (bond stretching, bond bending, and torsion) is generated. One of the trial positions is selected according to the Boltzmann weight of the external energy (nonbonded intramolecular, intermolecular, and alkane-zeolite), and this selected trial orientation is used to place the next atom of the chain. The procedure is repeated until the entire molecule has been grown. The rules for acceptance or rejection of a grown molecule are chosen in such a way that they exactly remove the bias caused by this growing scheme. Simulations are performed in cycles, and in each cycle, one move is chosen at random with a fixed probability of performing a molecule displacement (0.15), rotation around the center of mass $(0.15)$, exchange with the reservoir (0.55), and partial regrowth of a molecule (0.15). Additionally, for mixtures, we include an identity change. ${ }^{55}$ The maximum translational displacements and rotational angle change are adjusted to achieve an acceptance probability of around $50 \%$. The total number of cations remains constant during simulations and only translation movements and regrow are considered for this type of particle. The simulation box obeys the minimum image convention with a potential cutoff of $13.8 \AA$, and it consists of 16 orthorhombic cells $(2 \times$ $2 \times 4, a=20.1 \AA, b=19.7 \AA$, and $c=13.1 \AA$ ). Periodic boundary conditions are applied in all directions.

Henry coefficients were computed in the $N V T$ ensemble ${ }^{48}$ using translation (0.1), rotation (0.1), partial regrowths $(0.1)$, and regrowths of the entire molecule (0.7). For the NVT 


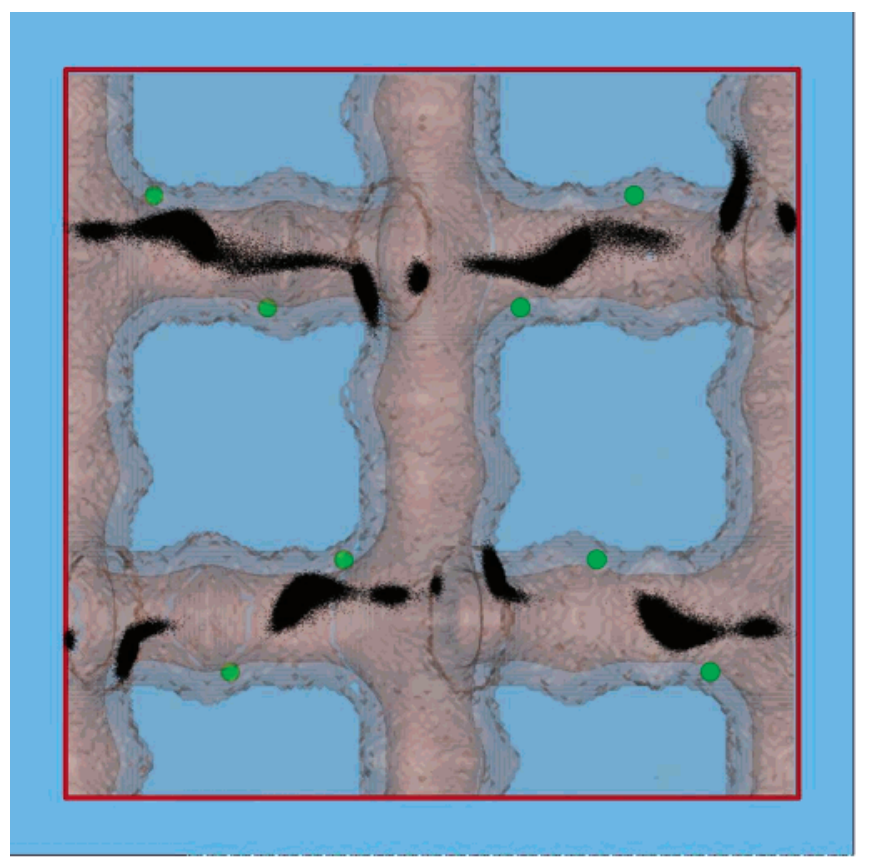

(a)

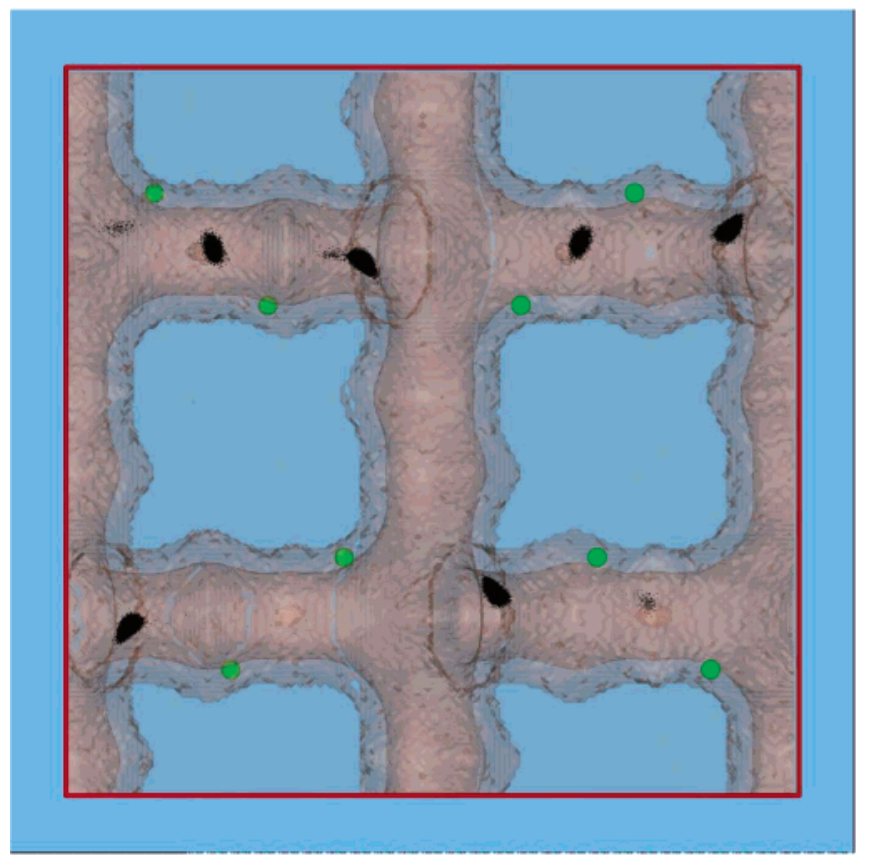

(c)

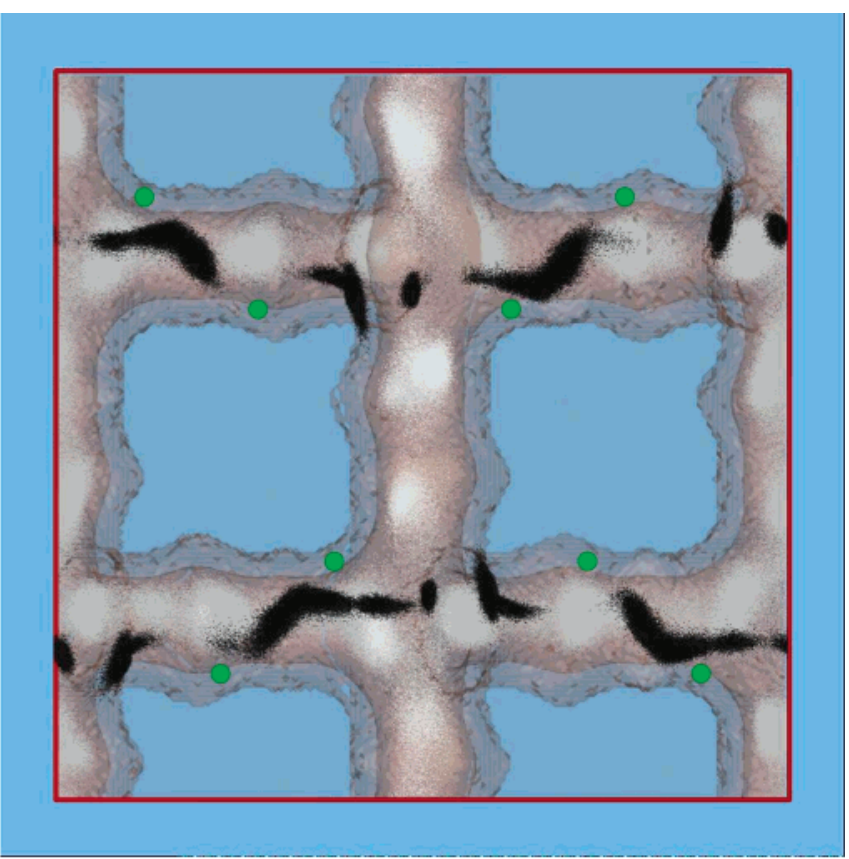

(b)

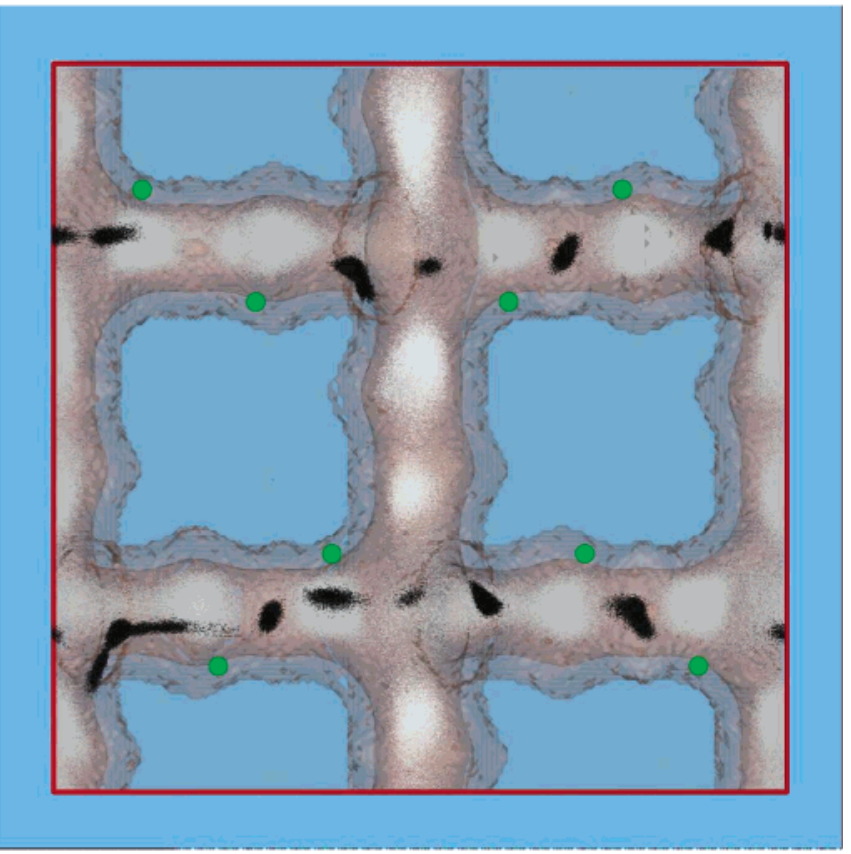

(d)

Figure 1. Distribution of the positions of the nonframework cations in MFI at $296 \mathrm{~K}$. The structure considered here contains eight Al/uc: (a) eight $\mathrm{Cs}^{+} / \mathrm{uc}$ in the empty zeolite; (b) eight $\mathrm{Cs}^{+} / \mathrm{uc}$ in butane-loaded zeolite at $10^{5} \mathrm{kPa}$; (c) four $\mathrm{Ba}^{2+} / \mathrm{uc}$ in the empty zeolite; (d) four Ba ${ }^{2+} / \mathrm{uc}$ in butaneloaded zeolite at $10^{5} \mathrm{kPa}$. In this figure, the zigzag channels are in the left-right direction and the straight channels in the top-bottom direction. The center of mass of the butane molecules are represented by white dots and the nonframework cation positions by dark dots. The aluminum positions are indicated by green circles.

simulations, the total number of cycles was at least $1 \times 10^{7}$. For the grand-canonical simulations, the number of cycles for one-component isotherms was $2 \times 10^{7}$ and at least $3 \times 10^{7}$ for the mixtures.

\section{Results and Discussion}

In this section, we present and discuss our results divided into three subsections: (i) location of nonframework cations, (ii) adsorption of alkanes, and (iii) adsorption selectivity.

3.1. Location of Nonframework Cations. We have used the orthorhombic crystallographic MFI structure of van Koningsveld et al. ${ }^{56}$ with 12 nonequivalent crystallographic T-sites. The position of the aluminum atoms in MFI are not easily characterized. Although many theoretical and experimental studies are undertaken to locate the aluminum positions, several discrepancies are found. Fripiat et al..$^{57}$ and Lonsinger et al. ${ }^{58}$ found that site $\mathrm{T} 12$ has the lowest energy for the substitution of $\mathrm{Al}$ for $\mathrm{Si}$ atoms. Olson et al ${ }^{59}$ found as preferred aluminum sites T4, T7, T10, T11, and T12, Redondo and Hay ${ }^{60}$ reported that, while there is small energy difference between the T12 sites, the site T9 is the favored for aluminum substitution, De Vos Burchart et al.$^{61}$ found preferential aluminum substitution in sites 
T2, T5, T6, T9, and T12, and Alvarado-Swaisgood et al. ${ }^{62}$ concluded that the most favorable sites for aluminum atoms are sites T6, T12, and T9. The disagreement on the positions of the aluminum lead some authors to develop the average T-site model ${ }^{63-65}$ However, because the locations of the cations are determined by the aluminum positions, we explicitly distinguish silicon (T1-T11) from aluminum sites (T12) because all previous authors agree in considering T12 a preferential site for aluminum.

We have performed Monte Carlo simulations to predict the location of nonframework cations in MFI. The location of cesium and barium nonframework cations in the empty zeolite with eight Al/uc and in alkane-loaded zeolite is shown in Figure 1. To compensate the negative net charge created by the aluminum in the structure, eight monovalent cesium cations or four divalent barium cations are considered (Figure 1 panels $\mathrm{a}, \mathrm{b}$ and $\mathrm{c}, \mathrm{d}$, respectively). Because of the strong Coulombic interactions with the zeolite framework, the energetically most favorable positions for the nonframework cations are near the oxygens binding aluminum atoms. Therefore, in the empty zeolite, we found that the cesium nonframework cations are distributed among these oxygens (Figure 1a), while the barium cations are found in the middle of the channels between opposite aluminum atoms (Figure 1c) because only four $\mathrm{Ba}^{+} / \mathrm{uc}$ are needed to compensate the net negative charge created by the eight $\mathrm{Al} / \mathrm{uc}$ of the framework.

The adsorption of alkanes in the zeolite is found to influence the location of the nonframework cations, especially at higher pressures. This influence is more important for the divalent cations as shown in Figure 1b,d where the distribution positions of cesium and barium in butane-loaded zeolite at $10^{5} \mathrm{kPa}$ are depicted. The presence of alkanes in the zeolite increases the number of positions where the barium cations can be located, while the cesium cations remain distributed among the oxygens binding aluminum atoms in a similar way as for the empty zeolite.

3.2. Adsorption of Alkanes. Adsorption isotherms were computed for methane (Figure 2), ethane (Figure 3), propane (Figure 4), butane (Figure 5), and isobutane (Figure 6) at 296 $\mathrm{K}$ in MFI structures with several amounts of cations. Our results show that density, size, and charge of nonframework cations influence the adsorption properties of these alkanes in MFItype structures. Due to the structural shape of MFI, straight channels that are intersected by zigzag channels, an increase in the amount of adsorption is observed with removal of cations from the channels and also with introduction of divalent cations (one divalent cation compensates the negative charge created by two $\mathrm{Al}$ atoms). Hence, alkanes reach the highest maximum loading in the pure silica structure (silicalite). In our previous work, we showed that the density of nonframework sodium cations in the zeolite provokes two different effects. ${ }^{25}$ The first effect was important in molecules with big pores where nonframework cations have favorable van der Waals interactions with the alkane molecules acting as an "extra wall" and creating extra adsorption sites in the zeolite. MFI forms medium-size channels, and therefore nonframework cations and alkane molecules do not fit next to each other in a pore, thus eliminating the favorable van der Waals interaction. The presence of nonframework cations in the zeolite provokes also an excluded volume effect. This second effect is important in MFI-type structures. Adding nonframework cations to the zeolite decreases the effective pore volume.

In the MFI structures considered here, the aluminum atoms are located at the intersections (for the structures with two and (a)

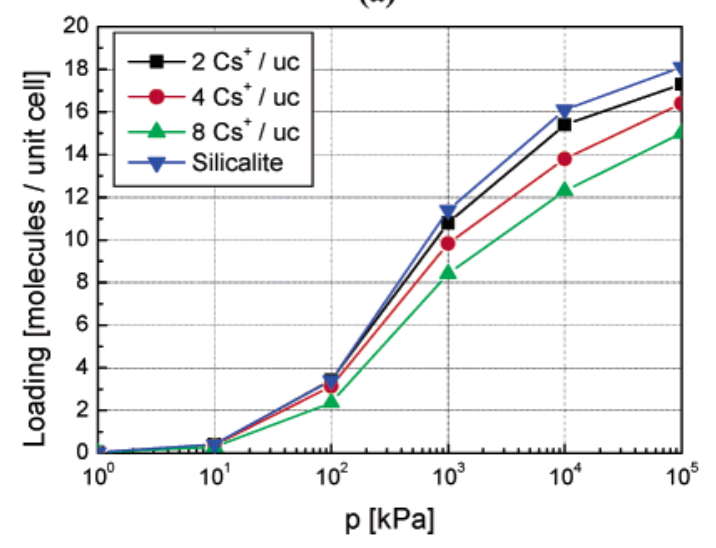

(b)

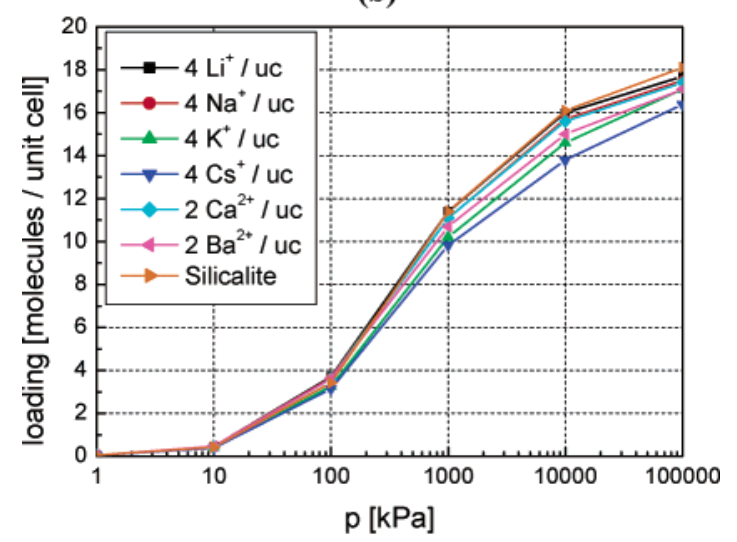

(c)

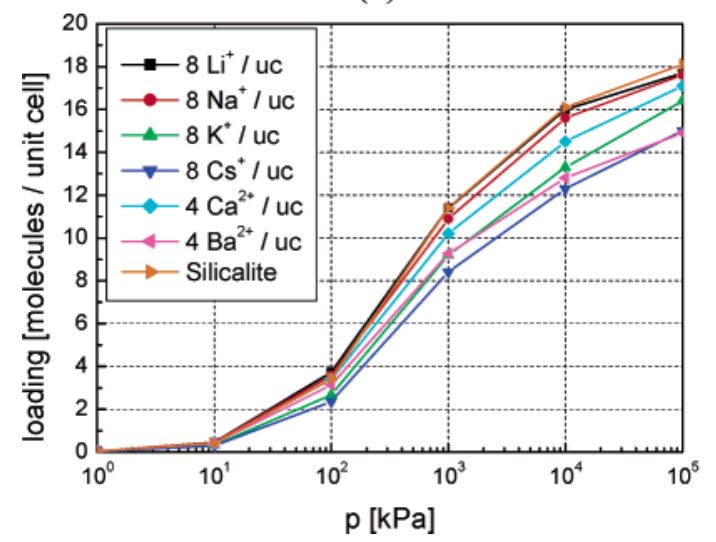

Figure 2. Simulated adsorption isotherms of methane in MFI-type zeolites at $296 \mathrm{~K}$ : (a) influence of the density of alkali nonframework cations for MFI structures with zero, two, four, and eight $\mathrm{Cs}^{+} / \mathrm{uc}$; (b) influence of the type of nonframework cations in a MFI structure with four aluminum atoms/uc; (c) influence of the type of nonframework cations in a MFI structure with eight aluminum atoms/uc.

four $\mathrm{Al} / \mathrm{uc}$ ) and also at the zigzag channels (for the structure with eight $\mathrm{Al} / \mathrm{uc}$ ). The nonframework cations are distributed near the oxygens binding the aluminum atoms. Therefore, these positions are partially blocked reducing the number of alkane molecules that fit inside the zeolite. Accordingly, we observed a clear decrease in the adsorption of alkanes with the increase of nonframework cations in the structure. Differences are minor for structures with small cations, such as lithium or sodium, but they become noteworthy for bigger cations, such as potassium and cesium, as shown for methane and ethane in Figures $2 \mathrm{a}$ and $3 \mathrm{a}$, respectively. The same behavior is true for the structures with alkali earth metal cations as observed in 
(a)

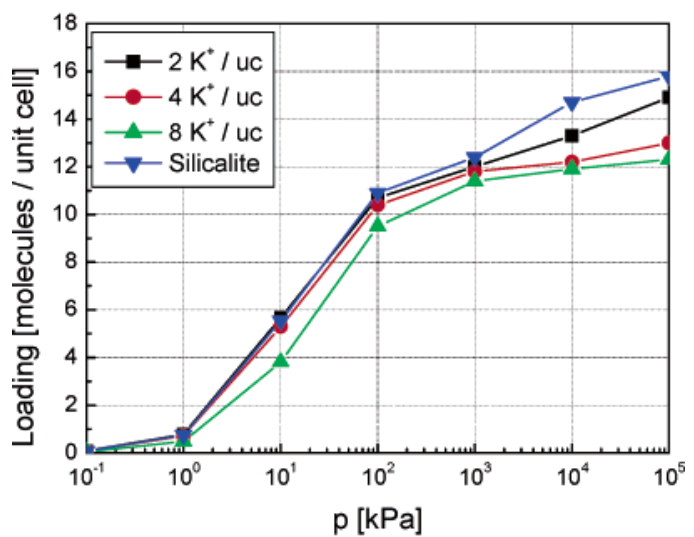

(b)

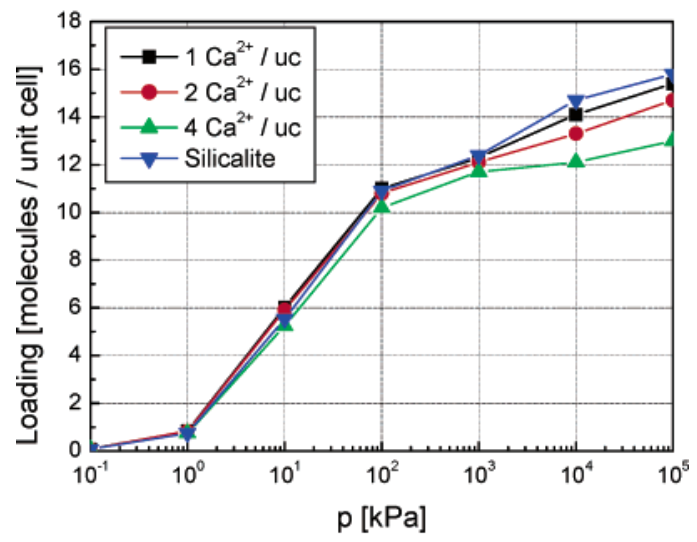

(c)

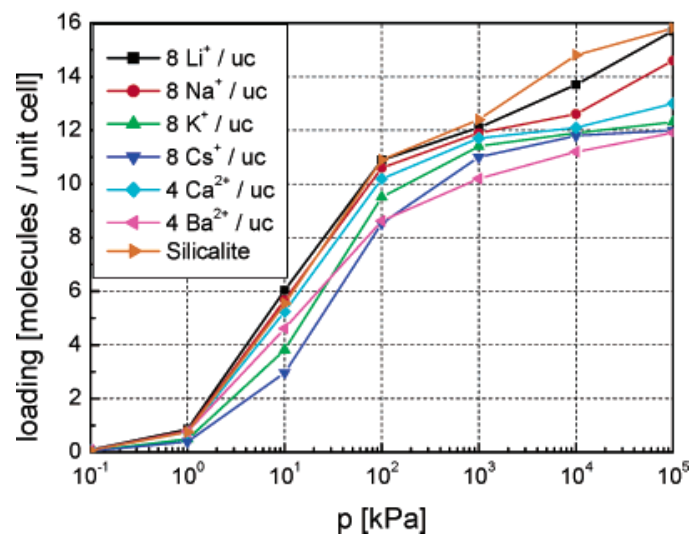

Figure 3. Simulated adsorption isotherms of ethane in MFI-type zeolites at $296 \mathrm{~K}$ : (a) influence of the density of alkali nonframework cations in MFI structures with zero, two, four, and eight $\mathrm{K}^{+} / \mathrm{uc}$; (b) influence of the density of alkali earth nonframework cations in MFI structures with zero, one, two, and four $\mathrm{Ca}^{2+} / \mathrm{uc}$; (c) influence of the type of nonframework cations in a MFI structure with eight aluminum atoms/uc.

Figure $3 \mathrm{~b}$ for the adsorption isotherms of ethane in four structures where the amount of calcium nonframework cations varies from zero to four $\mathrm{Ca}^{2+} / \mathrm{uc}$.

Panels $\mathrm{a}-\mathrm{c}$ of Figure 3 show the computed adsorption isotherms for ethane in several MFI-type structures. Note that for silicalite there is an additional rise in the adsorption isotherm of ethane near the maximum loading. This rise decreases and even disappears with the introduction of nonframework cations into the zeolite channel. This small inflection point at high pressures was already observed in previous works, ${ }^{25,66}$ and it is

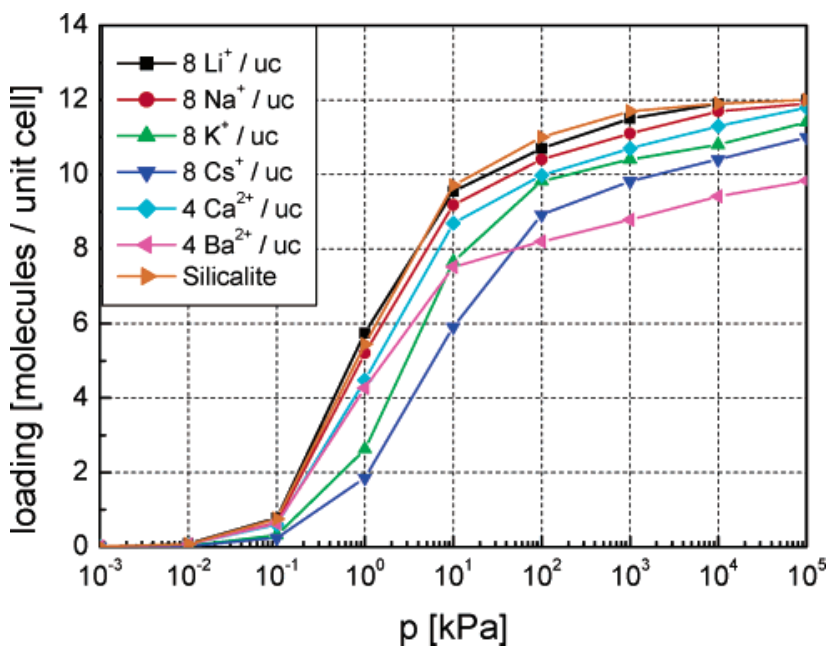

Figure 4. Effect of the size of nonframework cations on the adsorption isotherms of propane at $296 \mathrm{~K}$ in MFI-type zeolites with eight aluminum atoms/uc.

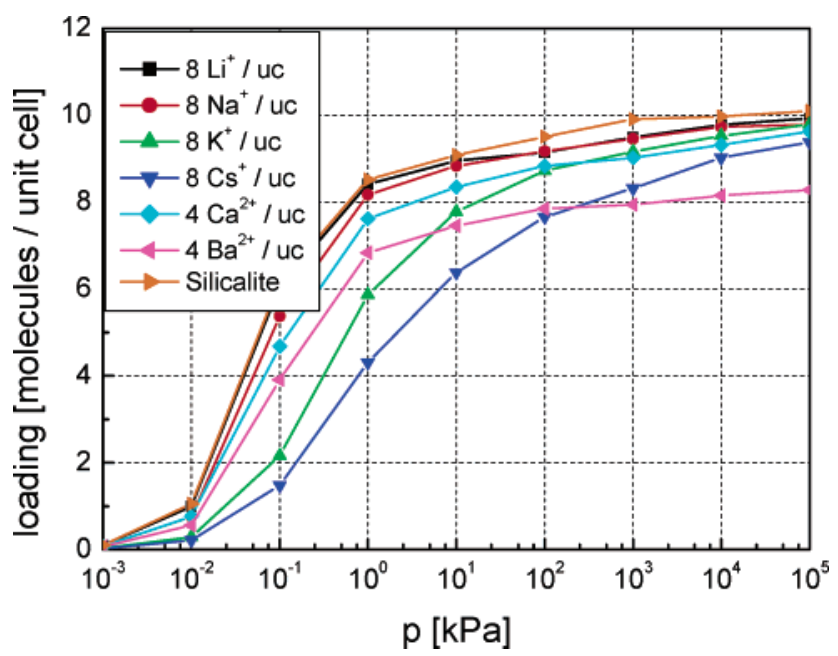

Figure 5. Effect of the size of nonframework cations on the adsorption isotherms of butane at $296 \mathrm{~K}$ in MFI-type zeolites with eight aluminum atoms/uc.

related to the commensurate freezing effect reported in 1995 by Smit and Maesen. ${ }^{67}$ Here, we found evidence that the inflection point observed at high pressures for ethane depends not only on the density of nonframework cations ${ }^{25}$ but also on the nature of the cation. As can be observed in Figure 3a,c, this rise disappears in the adsorption isotherm corresponding to the structure with the highest nonframework cation density (eight $\mathrm{K}^{+} / \mathrm{uc}$ ), as well as in the adsorption isotherms corresponding to the structures with the biggest cations $\left(\mathrm{Cs}^{+}\right.$and $\left.\mathrm{Ba}^{2+}\right)$.

The limiting factor during adsorption can be either the density, the size, or the charge of the nonframework cations depending on the pressure regime and on the type of adsorbate. Table 2 shows the Henry coefficient obtained from our simulations. In the Henry regime, both size and density of nonframework cations determine the adsorption, and the Henry coefficients decrease with increasing nonframework cation concentration or size of the cation. At higher pressures, not only the density and the size but also the charge of nonframework cations influence the adsorption. Figure $2 \mathrm{~b}$ shows adsorption isotherms for methane in MFI structures with four and eight $\mathrm{Al} / \mathrm{uc}$, where the negative net charge of the framework has been compensated using different cations. Note that for a structure with $n \mathrm{Al} / \mathrm{uc}$, $n$ alkali or $n / 2$ alkali earth nonframework cations/uc are needed to obtain an electrostatically neutral system. As shown in Figure 
(a)

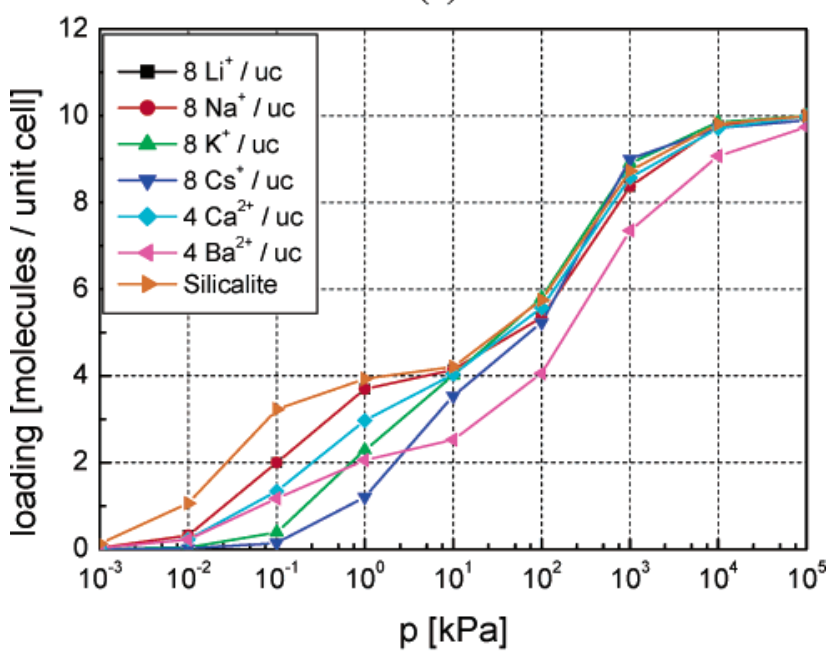

(b)

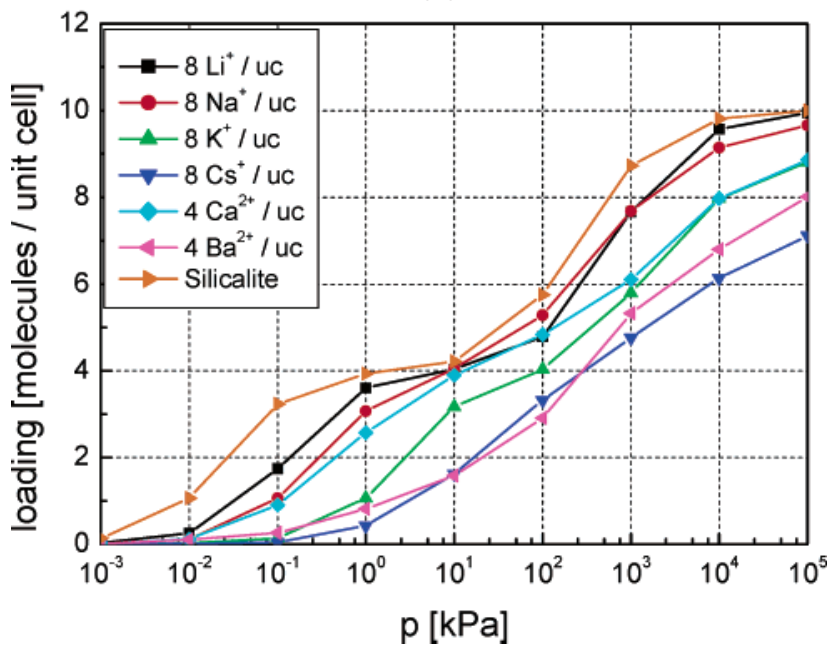

Figure 6. Effect of the size of nonframework cations on the adsorption isotherms of isobutane in MFI-type zeolites: (a) four aluminum atoms/ uc; (b) eight aluminum atoms/uc.

$2 \mathrm{~b}$, for the complete range of pressures, the adsorption of methane in the structure with four $\mathrm{Al} / \mathrm{uc}$ reaches its maximum values for the structure with the smallest cations, that is, lithium and sodium. Moreover, adsorption for the structure with calcium and barium nonframework cations is higher than that for potassium and cesium, indicating that for this particular structure the adsorption is influenced more by the amount of nonframework cations than by their charge. Similarly, in the structure corresponding to eight $\mathrm{Al} / \mathrm{uc}$, the adsorption of methane is higher with calcium (four $\mathrm{Ca}^{2+} / \mathrm{uc}$ ) than with potassium (eight $\mathrm{K}^{+}$/ uc). However, adsorption behavior for structures with barium and cesium becomes more complex, and from $10^{5} \mathrm{kPa}$, methane appears to adsorb slightly better in the structure with barium than in the structure with cesium (Figure 2c). This effect is more pronounced for longer molecules. Figure $3 \mathrm{~b}$ shows the adsorption isotherms of ethane for the structure with eight $\mathrm{Al} / \mathrm{uc}$. In the range of pressures that spans from $10^{-1}$ to $10^{2} \mathrm{kPa}$, it is mainly the density of cations that influences the adsorption of the alkanes, and for a defined structure there are twice more alkali than calcium cations, ethane adsorption in structures with alkali earth metal cations $\left(\mathrm{Ca}^{2+}\right.$ and $\left.\mathrm{Ba}^{2+}\right)$ is higher than in structures with alkali metal cations $\left(\mathrm{K}^{+}\right.$and $\left.\mathrm{Cs}^{+}\right)$. At higher pressures, the ethane molecules completely fill the channels, and then both density and charge of the nonframework cations (a)

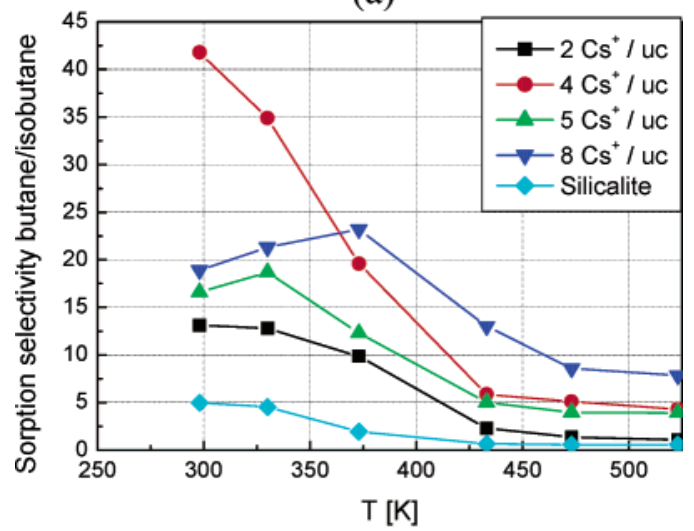

(b)

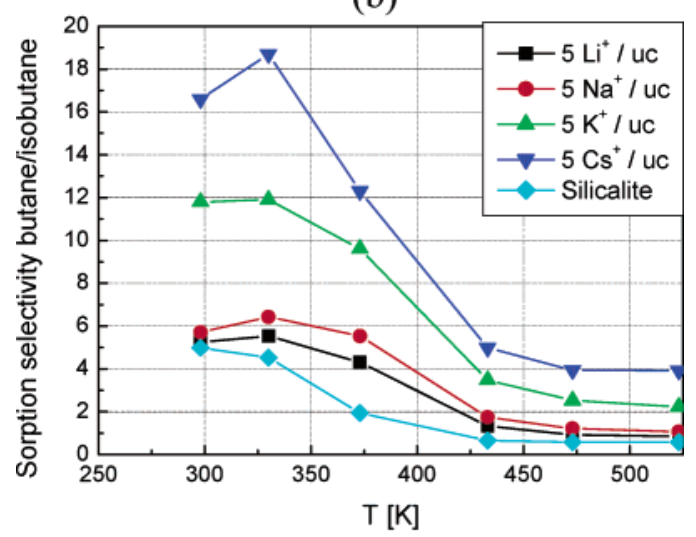

(c)

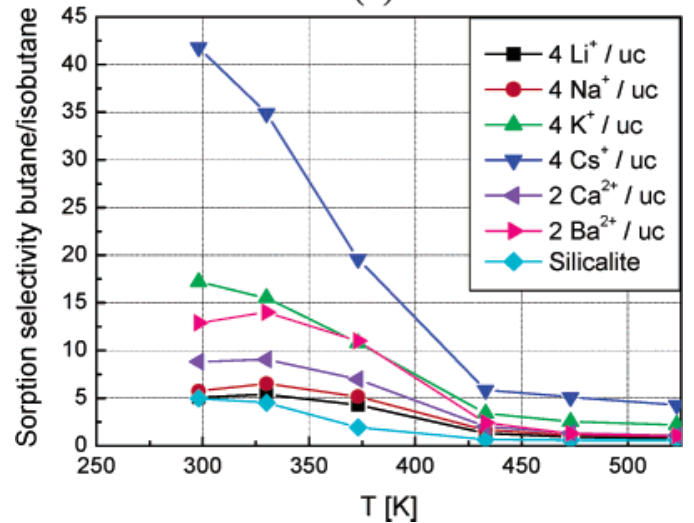

Figure 7. Butane/isobutane adsorption selectivity as a function of temperature obtained from CBMC simulations in MFI-type zeolites at $10^{2} \mathrm{kPa}$ : (a) Influence of the density of cesium nonframework cations in MFI structures with zero, two, four, five, and eight $\mathrm{Cs}^{+} / \mathrm{uc}$; (b) influence of the type of alkali metal nonframework cation in a MFI structure with five aluminum atoms/uc; (c) influence of the type of nonframework cations in a MFI structure with four aluminum atoms/ uc.

become limiting factors for adsorption. As a result, from $10^{2}$ $\mathrm{kPa}$, the adsorption of ethane is higher in the structure with cesium than in the one with barium but still remains better in the structure with calcium than in the structure with potassium. Propane and butane adsorption isotherms were also obtained for the same structures and in the same conditions as those for methane and ethane. Again, the adsorption of propane and butane is higher in pure silica MFI than in the structures with aluminum, decreasing with the increase of nonframework cation density. Figures 4 and 5 show, respectively, the adsorption isotherms of propane and butane in an MFI structure with eight 
TABLE 2: Henry Coefficients ( $\mathrm{mol} \mathrm{kg} \mathrm{kg}^{-1} \mathrm{~Pa}^{-1}$ ) of Methane, Ethane, Propane, Butane, and Isobutane in Various MFI-type Zeolites at $296 \mathrm{~K}$

\begin{tabular}{|c|c|c|c|c|c|}
\hline structure & methane & ethane & propane & butane & isobutane \\
\hline \multicolumn{6}{|c|}{ Silicalite } \\
\hline & $7.39 \times 10^{-6}$ & $1.32 \times 10^{-4}$ & $1.24 \times 10^{-3}$ & $1.59 \times 10^{-2}$ & $2.33 \times 10^{-2}$ \\
\hline \multicolumn{6}{|c|}{$\mathrm{Si} / \mathrm{Al}=47$} \\
\hline $2 \mathrm{Li}^{+} / \mathrm{uc}$ & $8.18 \times 10^{-6}$ & $1.52 \times 10^{-4}$ & $1.48 \times 10^{-3}$ & $1.95 \times 10^{-2}$ & $6.78 \times 10^{-3}$ \\
\hline $2 \mathrm{Na}^{+} / \mathrm{uc}$ & $8.10 \times 10^{-6}$ & $1.52 \times 10^{-4}$ & $1.43 \times 10^{-3}$ & $1.87 \times 10^{-2}$ & $5.66 \times 10^{-3}$ \\
\hline $2 \mathrm{~K}^{+} / \mathrm{uc}$ & $7.61 \times 10^{-6}$ & $1.38 \times 10^{-4}$ & $1.22 \times 10^{-3}$ & $1.61 \times 10^{-2}$ & $4.11 \times 10^{-3}$ \\
\hline $2 \mathrm{Cs}^{+} / \mathrm{uc}$ & $7.27 \times 10^{-6}$ & $1.30 \times 10^{-4}$ & $1.14 \times 10^{-3}$ & $1.49 \times 10^{-2}$ & $3.75 \times 10^{-3}$ \\
\hline $1 \mathrm{Ca}^{2+} / \mathrm{uc}$ & $8.10 \times 10^{-6}$ & $1.51 \times 10^{-4}$ & $1.43 \times 10^{-3}$ & $1.95 \times 10^{-2}$ & $5.94 \times 10^{-3}$ \\
\hline $1 \mathrm{Ba}^{2+} / \mathrm{uc}$ & $7.97 \times 10^{-6}$ & $1.48 \times 10^{-4}$ & $1.41 \times 10^{-3}$ & $1.92 \times 10^{-2}$ & $5.79 \times 10^{-3}$ \\
\hline \multicolumn{6}{|c|}{$\mathrm{Si} / \mathrm{Al}=23$} \\
\hline $4 \mathrm{Li}^{+} / \mathrm{uc}$ & $8.10 \times 10^{-6}$ & $1.51 \times 10^{-4}$ & $1.43 \times 10^{-3}$ & $1.79 \times 10^{-2}$ & $5.97 \times 10^{-3}$ \\
\hline $4 \mathrm{Na}^{+} / \mathrm{uc}$ & $7.95 \times 10^{-6}$ & $1.49 \times 10^{-4}$ & $1.35 \times 10^{-3}$ & $1.68 \times 10^{-2}$ & $3.97 \times 10^{-3}$ \\
\hline $4 \mathrm{~K}^{+} / \mathrm{uc}$ & $7.02 \times 10^{-6}$ & $1.23 \times 10^{-4}$ & $9.36 \times 10^{-4}$ & $1.14 \times 10^{-2}$ & $6.96 \times 10^{-4}$ \\
\hline $4 \mathrm{Cs}^{+} / \mathrm{uc}$ & $6.40 \times 10^{-6}$ & $1.08 \times 10^{-4}$ & $7.65 \times 10^{-4}$ & $9.06 \times 10^{-3}$ & $2.04 \times 10^{-4}$ \\
\hline $2 \mathrm{Ca}^{2+} / \mathrm{uc}$ & $7.96 \times 10^{-6}$ & $1.48 \times 10^{-4}$ & $1.33 \times 10^{-3}$ & $1.81 \times 10^{-2}$ & $4.38 \times 10^{-3}$ \\
\hline $2 \mathrm{Ba}^{2+} / \mathrm{uc}$ & $7.99 \times 10^{-6}$ & $1.48 \times 10^{-4}$ & $1.33 \times 10^{-3}$ & $1.74 \times 10^{-2}$ & $4.12 \times 10^{-3}$ \\
\hline \multicolumn{6}{|c|}{$\mathrm{Si} / \mathrm{Al}=11$} \\
\hline $8 \mathrm{Li}^{+} / \mathrm{uc}$ & $8.17 \times 10^{-6}$ & $1.51 \times 10^{-4}$ & $1.35 \times 10^{-3}$ & $1.73 \times 10^{-2}$ & $4.55 \times 10^{-3}$ \\
\hline $8 \mathrm{Na}^{+} / \mathrm{uc}$ & $7.74 \times 10^{-6}$ & $1.38 \times 10^{-4}$ & $1.09 \times 10^{-3}$ & $1.29 \times 10^{-2}$ & $1.87 \times 10^{-3}$ \\
\hline $8 \mathrm{~K}^{+} / \mathrm{uc}$ & $5.61 \times 10^{-6}$ & $8.28 \times 10^{-5}$ & $5.17 \times 10^{-4}$ & $4.73 \times 10^{-3}$ & $2.20 \times 10^{-4}$ \\
\hline $8 \mathrm{Cs}^{+} / \mathrm{uc}$ & $4.34 \times 10^{-6}$ & $5.86 \times 10^{-5}$ & $3.26 \times 10^{-4}$ & $3.06 \times 10^{-3}$ & $8.41 \times 10^{-5}$ \\
\hline $4 \mathrm{Ca}^{2+} / \mathrm{uc}$ & $7.45 \times 10^{-6}$ & $1.30 \times 10^{-4}$ & $1.07 \times 10^{-3}$ & $1.35 \times 10^{-2}$ & $2.37 \times 10^{-3}$ \\
\hline $4 \mathrm{Ba}^{2+} / \mathrm{uc}$ & $7.02 \times 10^{-6}$ & $1.31 \times 10^{-4}$ & $9.20 \times 10^{-4}$ & $1.36 \times 10^{-2}$ & $9.45 \times 10^{-4}$ \\
\hline
\end{tabular}

$\mathrm{Al} / \mathrm{uc}$. Note that in the range of pressures spanning from $10^{-3}$ to $10^{2} \mathrm{kPa}$ the adsorption in the structures with four alkali earth cations/uc $\left(\mathrm{Ca}^{2+}\right.$ and $\left.\mathrm{Ba}^{2+}\right)$ is higher than that in the structures with eight alkali nonframework cations $\left(\mathrm{K}^{+}\right.$and $\left.\mathrm{Cs}^{+}\right)$. Nevertheless, at higher pressures, both propane and butane reach the lowest adsorption for the structure with four $\mathrm{Ba}^{2+} / \mathrm{uc}$. Figure 1 provides an explanation of this behavior based on how the location of the nonframework cations influences the adsorption of alkanes.

Adsorption isotherms of isobutane at $296 \mathrm{~K}$ for MFI structures with zero, two, four, and eight Al/uc are shown in Figure 6a,b. As for the previous systems, the adsorption in pure silica MFI is higher than the adsorption in MFI with $\mathrm{Al}$ substitutions. In the low-pressure range that spans from $10^{-2}$ to $1 \mathrm{kPa}$, the adsorption of isobutane is higher for the structures with alkali earth metal nonframework cations $\left(\mathrm{Ca}^{2+}\right.$ and $\left.\mathrm{Ba}^{2+}\right)$ than for the structures with alkali metals $\left(\mathrm{K}^{+}\right.$and $\left.\mathrm{Cs}^{+}\right)$. This behavior is as for linear alkanes, although at lower pressures because of the selective adsorption of branched alkanes at the intersections. When the pressure is increased, the size of the nonframework cations becomes more important than the density, and therefore, for the structure with four $\mathrm{Al} / \mathrm{uc}$, the adsorption is noticeably lower for two $\mathrm{Ba}^{2+}$ than for four $\mathrm{Cs}^{+} / \mathrm{uc}$. In the structure with eight $\mathrm{Al} / \mathrm{uc}$, the aluminum atoms are located not only in the intersections but also in the channels. Some of the cations are also located in the channels leading to differences in adsorption over the complete range of pressures. At low pressure, the adsorption follows the same behavior as that observed for the structure with four $\mathrm{Al} / \mathrm{uc}$, that is, isobutane adsorbs more poorly in structures with higher density of cations. At higher pressures differences in the adsorption behavior are observed for the structures with barium, potassium, and cesium. From $1 \mathrm{kPa}$, the adsorption in the structure with eight $\mathrm{K}^{+}$increases in comparison with the adsorption for the structures containing eight $\mathrm{Cs}^{+}$and four $\mathrm{Ba}^{2+} / \mathrm{uc}$. At the highest pressures in the structure with four $\mathrm{Al} / \mathrm{uc}$, the lowest adsorption for isobutane is given with barium nonframework cations (two $\mathrm{Ba}^{2+} / \mathrm{uc}$ ). The same is true for the structure with eight $\mathrm{Al} / \mathrm{uc}$ in the pressure range that spans from 10 to $150 \mathrm{kPa}$. However, for pressures higher than $150 \mathrm{kPa}$, the density becomes more important than the charge of the cations and the adsorption is lower for the structure containing eight $\mathrm{Cs}^{+} / \mathrm{uc}$ than from the structure with four $\mathrm{Ba}^{2+} / \mathrm{uc}$ (Figure 6b).

3.3. Adsorption Selectivity. It is worthwhile to highlight the differences in adsorption between the two isomers. As shown in Figure 5, density and size of nonframework cations determine the amount of butane adsorbed at low pressures, whereas charge of the nonframework cation determines the adsorption behavior of butane at high pressures. Because the preferential adsorption sites of branched alkanes are the intersections, ${ }^{68}$ the influence of density and nature of nonframework cations on the adsorptive properties of isobutane in MFI structures at low pressures becomes larger than that for butane. In contrast, at high pressures when some the molecules of isobutane can also be adsorbed in the channels, the influence of the nonframework cations on the adsorption of isobutane is negligible in comparison with the influence exerted for the adsorption of butane (Figure 6a).

Separation of alkanes in zeolites is based on differences in diffusion rates, adsorption, and molecular size. To test the influence of the nonframework type and density in isomer separations, we have carried out simulations to obtain the adsorption of a 50/50 (equimolar) mixture of butane and isobutane in MFI zeolites. Simulations were performed at $10^{2}$ $\mathrm{kPa}$ over a temperature range of $300-525 \mathrm{~K}$. For each binary system, five types of nonframework cations at five aluminum densities (Si/Al ratios) have been considered. Figure 7 shows the butane/isobutane adsorption selectivity (defined by $S=\left(\theta_{1} /\right.$ $\left.\theta_{2}\right) /\left(p_{1} / p_{2}\right)$ where $\theta_{i}$ and $p_{i}$ represent the component loading and partial pressure in the gas phase, respectively ${ }^{23}$ ) as a function of temperature for MFI structures with zero, two, four, five, and eight nonframework cations/uc. As could be expected, these selectivities decrease with increasing temperature. Independent of the cation density and type, the adsorption selectivity is in favor of $n$-butane.

The adsorption selectivity for MFI structures with $\mathrm{Cs}^{+}$as the nonframework cation is shown in Figure 7a. In the range of low temperatures $(298-330 \mathrm{~K})$ the butane/isobutane separation selectivity increases with the number of cations up to four $\mathrm{Cs}^{+} /$ uc. Surprisingly, sorption selectivity decreases for the structure corresponding to eight $\mathrm{Cs}^{+} / \mathrm{uc}$ and even more for the one with five $\mathrm{Cs}^{+} / \mathrm{uc}$. This behavior is mainly due to the distribution of the nonframework cations in the MFI structures. In the tem- 
perature range that spans from 330 to $525 \mathrm{~K}$, the adsorption of butane decreases when temperature increases independent of the density of nonframework cations. However, the adsorption of isobutane in this range of temperatures depends on the density of nonframework cations. For four and five $\mathrm{Cs}^{+} / \mathrm{uc}$ adsorption of isobutane is almost the same, and it decreases for eight $\mathrm{Cs}^{+} /$ uc. Because adsorption of linear alkanes is higher for the structure with four cations than for the structure with five cations, the adsorption selectivity ( $\left.\theta_{\text {butane }} / \theta_{\text {isobutane }}\right)$ is higher for the former structure than for the latter. Even though the adsorption of linear alkanes decreases with the density of nonframework cations, the structure with eight $\mathrm{Cs}^{+} / \mathrm{uc}$ shows the highest selectivity in this range of temperatures. This is due to the negligible adsorption of branched alkanes.

Figure $7 \mathrm{~b}$ shows similar temperature dependencies for butane/ isobutane adsorption selectivities in MFI zeolites with different types of nonframework cations. For the range of temperatures considered here, the adsorption in favor of the linear alkane is larger for the biggest cations, that is, the structure containing cesium provides the highest selectivity for the linear alkane, followed by the structures containing potassium, sodium, and lithium. Note that for the structures containing cations the sorption selectivity decreases both at the lowest and at the highest temperatures with a maximum around $325 \mathrm{~K}$. As observed for pure silica structures, the decrease at the highest temperatures is due to the lower total loading at these conditions. The selectivity decrease at the lowest temperature is only observed in the structures with nonframework cations. This behavior is caused by a size entropy effect. ${ }^{23,25}$ At these conditions and when the zeolite almost reached its saturation loading, only isobutane can enter the zeolite, slowly decreasing the butane/isobutane sorption selectivity. Finally, Figure $7 \mathrm{c}$ shows that for a fixed $\mathrm{Al}$ content density of nonframework cations becomes more important than charge. Thus, for a MFI structure containing four $\mathrm{Al} / \mathrm{uc}$, the highest selectivity is obtained for the structure with four $\mathrm{Cs}^{+} / \mathrm{uc}$. A lower and almost similar selectivity is observed for the structures with four $\mathrm{K}^{+} / \mathrm{uc}$ and two $\mathrm{Ba}^{2+} / \mathrm{uc}$, and it decreases even more for the structures with two $\mathrm{Ca}^{2+}$, four $\mathrm{Na}^{+}$, and four $\mathrm{Li}^{+} / \mathrm{uc}$.

\section{Conclusions}

In this work, we have performed a theoretical study of the influence of nonframework cations in the adsorptive properties of alkanes in MFI-type zeolites. In these structures, the density and nature (size and charge) of nonframework cations induced marked variations in the sorption isotherms of alkanes. We have used CBMC simulations to provide an explanation for this behavior. First, for a given cation, the adsorption of the alkanes in the MFI structure increases with decreasing nonframework cation concentration. In addition, for a 50/50 butane/isobutane mixture, we show here that increasing the nonframework cation density from one to four cations/uc increasingly blocks the intersections and thereby increases the selectivity of MFI for adsorbing butane. By contrast, increasing the density by more than four nonframework cations/uc decreases the selectivity for these alkanes. Second, for a given chemical composition of the framework (fixed $\mathrm{Si} / \mathrm{Al}$ ratio), the adsorption of the alkanes in the MFI structure increases with decreasing atomic weight of the nonframework cation converging to the all-silica adsorption isotherm. In addition, the selectivity for adsorbing butane increases for the nonframework cations with an increase in size.

Acknowledgment. These investigations are supported in part by The Netherlands Research Council for Chemical Sciences
(CW) through PIONIER. We thank the European Commission for the support through a Marie Curie Individual Research Fellowship.

\section{References and Notes}

(1) van Santen, R. A.; Kramer, G. J. Chem. Rev. 1995, 95, 637.

(2) Zecchina, A.; Otero Areán, C. Chem. Soc. Rev. 1996, 25, 187.

(3) Olson, D. H.; Kokotailo, G. T.; Lawton, S. L.; Meier, W. M. J. Phys. Chem. 1981, 85, 2238.

(4) Flanigen, E. M.; Bennet, J. M.; Grose, J. M.; Cohen, R. W.; Patton, J. P.; Kirchen, R. L.; Smith, R. M. Nature 1978, 271, 512.

(5) van Bekkum, H., Flaningen, E. M., Janse, J. C., Eds. Studies in Surface Science and Catalysis; Elsevier Science B. V.: Amsterdam, 1991; Vol. 58.

(6) Smith, J. V. Adv. Chem. Ser. 1971, 101, 171.

(7) Grey, C. P.; Poshni, F. I.; Gualtieri, A. F.; Norby, P.; Hanson, J. C.; Corbin, D. R. J. Am. Chem. Soc. 1997, 119, 1989

(8) Jaramillo, E.; Grey, C. P.; Auerbach, S. M. J. Phys. Chem. B 2001, 105,12319 .

(9) Kolotailo, G. T.; Lawson, S. L.; Olson, D. H.; Meier W. M. Nature 1978, 272, 437 .

(10) International Zeolite Association Structure Commission. http:// www.iza-structure.org (accessed December 10, 2002).

(11) Meier, W. M.; Olson D. H. Atlas of Zeolite Structure Types; Butterworth-Heinemann: London, 1992.

(12) Yan, Y. H.; Tsapatsis, M.; Gavalas, G. R.; Davis, M. E. J. Chem Soc., Chem. Commun. 1995, 227.

(13) Vroon, Z. A. E. P.; Keizer, K.; Gilde, M. J.; Verweij, H.; Burggraaf, A. J. J. Membr. Sci. 1996, 113, 293.

(14) Coronas, J.; Noble, R. D.; Falconer, J. L. Ind. Eng. Chem. Res. 1998, 37,166

(15) Krishna, R.: Smit, B.; Calero, S. Chem. Soc. Rev. 2002, 31, 185

(16) Auerbach, S. M.; Kärger, J.; Vasenkov, S. Diffusion in zeolites. In Handbook of Zeolite Science and Technology; Auerbach, S. M., Carrado, K. A., Dutta, P. K., Eds.; Marcel Dekker Inc.: New York, 2003.

(17) Lachet, V.; Boutin, A.; Tavitian, B.; Fuchs, A. H. Faraday Discuss. 1997, 106, 307.

(18) Krishna, R.; Smit, B.; Vlugt, T. J. H. J. Phys. Chem. A 1998, 102, 7727.

(19) Mellot, C. F.; Cheetham, A. K.; Harms, S.; Savitz, S.; Gorte, R. J.; Myers, A. L. J. Am. Chem. Soc. 1998, 120, 5788.

(20) Macedonia, M. D.; Maginn, E. J. Mol. Phys. 1999, 96, 1375.

(21) Schenk, M.; Vidal, S. L.; Vlugt, T. J. H.; Smit, B.; Krishna, R. Langmuir 2001, 17, 1558.

(22) Calero, S.; Smit, B.; Krishna, R. Phys. Chem. Chem. Phys. 2001, 3,4390 .

(23) Calero, S.; Smit, B.; Krishna, R. J. Catal. 2001, 202, 395.

(24) Calleja, G.; Pau, J.; Callas, J. A. J. Chem. Eng. Data 1998, 43, 944.

(25) Beerdsen, E.; Smit, B.; Calero, S. J. Phys. Chem. B 2002, 106, 10659 .

(26) Tuan, V. A.; Falconer, J. L.; Noble, R. D. Microporous Mesoporous Mater. 2000, 41, 269.

(27) Ciavarella, P.; Moueddeb, H.; Miachon, S.; Fiaty, K.; Dalmon, J. A. Catal. Today 2000, 56, 253

(28) van de Graaf, J. M. Ph.D. Thesis, Technical University of Delft, The Netherlands, 1999.

(29) Moissette, A.; Bremard, C. Microporous Mesoporous Mater. 2001, 47,345

(30) Moissette, A.; Gener, I.; Bremard C. J. Phys. Chem. B 2001, 105 , 5647

(31) Gener, I.; Buntinx, G.; Bremard, C. Microporous Mesoporous Mater. 2000, 41, 253.

(32) Savitz, S.; Myers, A. L.; Gorte, R. J. Microporous Mesoporous Mater. 2000, 37, 33.

(33) Ricchiardi, G, Newsam, J. M. J. Phys. Chem. B 1997, 101, 9943

(34) Gaffney, T. R. Curr. Opin. Solid State Mater. Sci. 1996, 1, 69

(35) Rep, M.; Palomares, A. E.; Eder-Mirth, G.; van Ommen, J. G.; Rosch, N.; Lercher, J. A. J. Phys. Chem. B 2000, 104, 8624.

(36) Armaroli, T.; Bevilacqua, M.; Trombetta, M.; Milella, F.; Alejandre, A. G.; Ramirez, J.; Notari, B.; Willey, R. J.; Busca, G. Appl. Catal., A 2001, 216,59

(37) Moissette, A.; Marquis, S.; Gener, I.; Bremard, C. Phys. Chem. Chem. Phys. 2002, 4, 5690

(38) Hadjiivanov, K.; Knozinger, H.; Milushev, A. Catal. Commun. 2002, 3, 37.

(39) Masuda, T.; Fukumoto, N.; Kitamura, M.; Mukai, S. R.; Hashimoto, K.; Tanaka, T.; Funabiki, T. Microporous Mesoporous Mater. 2001, 48 , 239.

(40) Herrero, C. P.; Ramirez, R. J. Phys. Chem. 1992, 96, 2246.

(41) Jaramillo, E.; Auerbach, S. M. J. Phys. Chem. B 1999, 103, 9589. 
(42) Demontis, P.; Suffritti, G. B. Chem. Rev. 1997, 97, 2845.

(43) Vlugt, T. J. H.; Schenk, M. J. Phys. Chem. B 2002, 106, 12757.

(44) Forester, T. R.; Smith, W. J. Chem. Soc., Faraday Trans. 21993 , 93, 3249 .

(45) Bouyermaouen, A.; Bellemans, A. J. Chem. Phys. 1998, 108, 2170.

(46) Jousse, F.; Vercauteren, D. P.; Auerbach, S. M. J. Phys. Chem. B 2000, 104, 8768.

(47) Smit, B. Mol. Phys. 1995, 85, 153

(48) Frenkel, D.; Smit, B. Understanding Molecular Simulations: From Algorithms to Applications, second edition; Academic Press: San Diego, CA, 2002.

(49) Ryckaert, J. P.; Bellemans, A. Faraday Discuss. Chem. Soc. 1978 66,95

(50) Siepmann, J. I.; Martin, M. G.; Mundy, C. J.; Klein, M. L. Mol. Phys, 1997, 90, 687.

(51) Vlugt, T. J. H.; Krishna, R.; Smit, B. J. Phys. Chem. B 1999, 103 1102.

(52) Bezus, A. G.; Kiselev, A. V.; Lopatkin, A. A.; Du, P. Q. J. Chem. Soc., Faraday Trans. 2 1978, 74, 367.

(53) Kiselev, A. V.; Lopatkin, A. A.; Shulga, A. A. Zeolites 1985, 5, 261.

(54) Rappé, A. K.; Casewit, C. J.; Colwell, K. S.; Goddard, W. A., III; Skiff, W. M. J. Am. Chem. Soc. 1992, 114, 10024.

(55) Martin, M. G.; Siepmann, J. I. J. Am. Chem. Soc. 1997, 119, 8921.
(56) van Koningsveld, H.; van Bekkum, H.; Jansen, J. C. Acta Crystallogr. 1987, B43, 127

(57) Fripiat, J. G.; Berger-Andre, F.; Andre, J.-M.; Derouane, E. G. Zeolites 1983, 3, 306 .

(58) Lonsinger, S. R.; Chakraborty, A. K.; Theodorou, D. N.; Bell, A. T. Catal. Lett. 1991, 11, 209.

(59) Olson, D. H.; Khosrovani, N.; Peters, A. W.; Toby, B. H. J. Phys. Chem. B 2000, 104, 4844.

(60) Redondo, A.; Hay, P. G. J. Phys. Chem. 1993, 97, 11754.

(61) de Vos Burchart, E.; van Bekkum, H.; van der Graaf, B. Collect. Czech. Chem. Commun. 1992, 57, 681.

(62) Alvarado-Swaisgood, A. E.; Barr, M. K.; Hay, P. J.; Redondo, A J. Phys. Chem. 1991, 95, 10031.

(63) Smirnov, K.; LeMaire, M.; Bremad, C.; Bougeard, D. Chem. Phys. 1994, $179,445$.

(64) Mellot, C. F.; Davidson, A. M.; Eckert, J.; Cheetham, A. K. J. Phys. Chem. B 1998, 102, 2530 .

(65) Auerbach, S. M.; Bull, L. M.; Henson, N. J.; Metiu, H. I.; Cheetham,

A. K. J. Phys. Chem. 1996, 100, 5923.

(66) Du, Z. M.; Manos, G.; Vlugt, T. J. H.; Smit, B. AIChE J. 1998 , $44,1756$.

(67) Smit, B.; Maesen, T. L. M. Nature 1995, 374, 42.

(68) Vlugt, T. J. H.; Zhu, W.; Kapteijn, F.; Moulijn, J. A.; Smit, B.; Krishna, R. J. Am. Chem. Soc. 1998, 120, 5599. 